\title{
Produção e conforto térmico de bovinos da raça Nelore terminados em sistemas integrados de produção agropecuária
}

[Production and thermal comfort of Nellore beef cattle

H.S. Aranha ${ }^{1}$, C. Andrighetto ${ }^{1}$, G.C. Lupatini ${ }^{1}$, L.G.F. Bueno ${ }^{1}$, G.A. Trivelin ${ }^{1}$, G.P. Mateus ${ }^{2}$, P.A.C. Luz ${ }^{3}$, J.M.F. Santos ${ }^{3}$, B.M.S. Sekiya ${ }^{3}$, R.F. $\mathrm{Vaz}^{4}$

${ }^{1}$ Universidade Estadual Paulista - Dracena, SP

${ }^{2}$ Agência Paulista de Tecnologia do Agronegócio - Andradina, SP

${ }^{3}$ Programa de pós-graduação - Universidade Estadual Paulista - Dracena, SP

${ }^{4}$ Programa de graduação - Universidade Estadual Paulista - Dracena, SP

\section{RESUMO}

O objetivo deste trabalho foi avaliar a pastagem, o desempenho, o conforto térmico e os parâmetros hematológicos de bovinos Nelore na fase de terminação em sistemas integrados de produção agropecuária com duas densidades de árvores (ILPF-1L= 196 árvores ha $^{-1}$ e ILPF-3L=448 árvores ha ${ }^{-1}$ ) e em pleno sol (ILP). Foram avaliados a massa e a composição morfológica da forragem, o ganho médio diário, o ganho de peso por área e a taxa de lotação no verão e no outono, bem como as variáveis climáticas dos sistemas em três horários e parâmetros hematológicos dos animais $(n=60)$. A massa de forragem foi superior no tratamento ILP e no verão $(\mathrm{P}<0,05)$. Porém, a redução da massa de forragem nos sistemas ILPFs não interferiu no desempenho dos animais $(\mathrm{P}>0,05)$. A temperatura ambiente, a temperatura do globo e o índice de temperatura e umidade foram melhores nos tratamentos com sombreamento e no período da manhã, proporcionando maior conforto aos animais, sendo ainda confirmado pelo menor volume globular dos bovinos em ILP $(\mathrm{P}<0,05)$. Conclui-se que os sistemas com componente arbóreo diminuem a massa de forragem, mas essa redução não altera o desempenho dos animais na fase de terminação. Além disso, os sistemas ILPFs melhoram o conforto térmico, entretando essa melhora não foi suficiente para favorecer o desempenho.

Palavras-chave: bem-estar, desempenho, massa de forragem, sistemas de integração lavoura-pecuáriafloresta

\begin{abstract}
The objective of this work was to evaluate pasture, performace, thermal comfort, and haematological parameters of Nellore cattle in the finishing phase in integrated crop-livestock systems with two tree densities (ICLF-1L=196 ha trees and ICLF-3L= $448 \mathrm{ha}^{-1}$ trees) and in full sun (ICL). The forage mass morphological composition of the pasture average daily gain, weight gain per area, stocking rate of the animals were evaluated in summer and autumn, and the climatic variables of systems we evaluated at three different times, and haematological parameters of the animals $(n=60)$. The forage mass was higher in the ICL treatment and summer $(P<0.05)$. However, the reduction of the forage mass in the ILPFs systems did not interfere with the performance of the animals $(P>0.05)$. Ambient temperature, globe temperature and temperature and humidity index were better in shade treatments and in the morning, providing greater comfort to the animals, and was also confirmed by the lower globular volume of the bovines in ICL $(P<0.05)$. It is concluded that the systems with trees reduce the forage mass but this
\end{abstract}

Recebido em 7 de abril de 2017

Aceito em 21 de março de 2019

E-mail: helena-aranha@live.com 
reduction does not alter the animals' performance in the finishing phase. In addition, ICLFs improve the thermal comfort of the animals, however, this improvement was not enough to favor their performance.

Keyword: welfare, performance, forage mass, integrated crop-livestock-forest systems

\section{INTRODUÇÃO}

O Brasil é caracterizado pelo maior rebanho comercial ( 194,0 milhões de cabeça, das quais $80 \%$ é representada pela raça Nelore) e maior exportador de carne bovina do mundo (Anuário..., 2018). Do total de cabeças de bovinos abatidas no ano de 2017 , cerca de $84 \%$ foram criadas e terminadas em pasto e apenas $16 \%$ em confinamento ou semiconfinamento (Anuário..., 2018). Entretanto, as pastagens brasileiras apresentam-se em evidente grau de degradação devido à sua exploração sem o uso de adubação e a práticas conservacionistas. Atualmente, as pastagens degradadas (isto é, com baixo rendimento forrageiro por área) cobrem aproximadamente 80 milhões de hectares no país (Crusciol et al., 2014). Diante desse cenário, a procura por alternativas que revertam a perda da qualidade do solo, visando ao aumento da produção vegetal em conjunto com a produção animal, é cada vez mais frequente.

Uma alternativa são os sistemas integrados de produção agropecuária (SIPAs), os quais têm como desafio se adaptar a sistemas profundamente direcionados a práticas conservacionistas (Moraes et al., 2014), sobretudo para reverter o processo de degradação dos solos (Castro Filho et al., 2002), pois oferecem incremento da fertilidade do solo, com fixação biológica do nitrogênio pelas leguminosas, aumentam a eficiência de ciclagem de nutrientes, melhoram as condições físicas do solo pelo efeito aglutinante da matéria orgânica, incrementam a microflora e a microfauna no horizonte superficial (Lal, 1991), além de reduzirem os riscos climáticos e meteorológicos, aumentando, assim, a sustentabilidade da produção agropecuária (Kichel et al., 2014).

Dentre as modalidades dos SIPAs, destaca-se a integração lavoura-pecuária (ILP), com benefícios significativos no solo, na forragem e, consequentemente, no desempenho animal. No entanto, a ILP apresentou, recentemente, novos avanços tecnológicos, introduzindo o componente arbóreo nas pastagens (Balbino et al., 2011). Esse avanço tecnológico se deve, sobretudo, ao fato de que boa parte das áreas das pastagens, especialmente no Brasil Central, encontram-se sob condições climáticas que determinam estresse calórico em graus mediano a severo no animal (Porfírio da Silva, 2003).

As altas temperaturas comprometem diretamente o desempenho animal, de forma que uma estratégia fisiológica dos bovinos durante o estresse térmico é diminuir a produção de calor metabólico reduzindo a ingestão de alimentos (Mitlöhner et al., 2002), o que acarreta redução do ganho de peso, elevação da idade de abate e do custo de produção. Além disso, o estresse térmico pode influenciar a osmolaridade e o volume sanguíneo de diversos ruminantes (Brasil et al., 2000; Singh et al., 2016). Nesse sentido, como o conforto térmico integra o conceito de bem-estar animal, e este último, por sua vez, pode influenciar no desempenho animal, o principal e mais importante fator a ser contornado em países tropicais é o efeito do clima, evitando-se que os animais sofram com o excessivo ganho de calor proveniente do ambiente (Pires et al., 2010).

Partindo da hipótese de que, nos sistemas integrados de produção agropecuária, a sombra das árvores de eucalipto pode influenciar no desempenho e bem-estar animal, o presente trabalho teve como objetivo avaliar a pastagem, o desempenho, o conforto térmico e os parâmetros hematológicos de bovinos da raça Nelore na fase de terminação em sistemas integrados de produção agropecuária com duas densidades de árvores e pastagem convencional.

\section{MATERIAL E MÉTODOS}

$\mathrm{O}$ experimento foi realizado de acordo com os princípios éticos na experimentação animal (Protocolo No 26/2014 - Ceua) determinados pela Comissão de Ética em Uso de Animais (Ceua) da referida instituição. O projeto iniciouse em dezembro de 2011, e detalhes do histórico da área são reportados por Luz et al. (2019). A área experimental localiza-se na Agência Paulista de Tecnologia dos Agronegócios - Apta, município de Andradina, SP $\left(20^{\circ} 53^{\prime}\right.$ de latitude 
sul, $51^{\circ} 22^{\prime}$ de longitude oeste e $405 \mathrm{~m}$ de altitude). O clima predominante na região é o Aw, segundo a classificação de Köppen-Geiger, caracterizando-se como tropical com inverno seco. O solo é do tipo Argisolo VermelhoAmarelo Distrófico com camada superficial arenosa e a declividade média do terreno é de $6 \%$. O período experimental foi de janeiro a junho de 2016, sendo caracterizado de janeiro a março o verão e de abril a junho o outono.

Foram utilizados 60 animais da raça Nelore, castrados, com $28 \pm 2,81$ meses de idade e pesos iniciais e finais de: $400 \mathrm{~kg}$ e $470 \mathrm{~kg} ; 368 \mathrm{~kg}$ e $441 \mathrm{~kg} ; 381 \mathrm{~kg}$ e $450 \mathrm{~kg}$ para os tratamentos de integração lavoura-pecuária (ILP), integração lavoura-pecuária-floresta com linha simples de eucalipto, sendo a distância entre linhas de 17 a $21 \mathrm{~m}$ e a distância entre plantas de $2 \mathrm{~m}$, com densidade de 196 árvores ha ${ }^{-1}$ (ILPF-1L) e integração lavoura-pecuária-floresta com linha tripla de eucalipto, sendo a distância entre linhas de eucalipto de $3 \mathrm{~m}$, a distância entre plantas de $2 \mathrm{~m}$ e a distância entre as faixas de eucalipto de 17 a $21 \mathrm{~m}$, com densidade de 448 árvores $\mathrm{ha}^{-1}$ (ILPF-3L), respectivamente. Os animais receberam, no período das águas, de janeiro a abril, suplemento contendo $20 \%$ de proteína bruta (PB) e $68 \%$ de nutrientes digestíveis totais (NDT), sendo o consumo de $0,1 \%$ do peso vivo. Em abril de 2016, iniciou-se a suplementação dos animais com $0,7 \%$ de concentrado (17\% PB e $82 \%$ NDT), os quais receberam essa suplementação até o abate.

Foi utilizada a pastagem de Urochloa brizantha cv. Marandu e o método de pastejo adotado foi o de lotação contínua e taxa de lotação variável, utilizando-se a técnica de put and take (Mott e Lucas, 1952). Em cada piquete, foram utilizados cinco animais testers e um número variável de reguladores, conforme a necessidade de ajuste da taxa de lotação para manutenção da meta de manejo, que era altura média do relvado de $30 \mathrm{~cm}$, apresentando 29,29 e $28 \mathrm{~cm}$ para ILP, ILPF-1L e ILPF-3L, respectivamente. O monitoramento da altura da pastagem nos piquetes foi realizado por meio de medições com régua graduada em centímetros a cada 14 dias. Para as avaliações do ganho de peso por área (GPA) e taxa de lotação (TL), foi subtraída a área ocupada pelos eucaliptos, sendo no ILPF-1L ocupação de $8 \%$ e no ILPF-3L de $28 \%$ da área.
A mensuração da massa de forragem foi realizada a partir do corte de todo material presente no interior de uma moldura com medidas de $1 \times 0,5 \mathrm{~m}\left(0,5 \mathrm{~m}^{2}\right)$ em nove pontos de cada piquete, uniformemente nas áreas sombreadas e em pleno sol. A forragem cortada foi pesada, homogeneizada e, posteriormente, foram retiradas duas amostras. A primeira amostra foi pesada e levada à estufa com circulação de ar forçada, para determinação da massa parcialmente seca, a $65^{\circ} \mathrm{C}$ até atingir peso constante. A segunda amostra foi utilizada para determinação da composição morfológica.

A composição morfológica foi realizada por separação manual dos seguintes componentes: lâmina foliar: compreendendo tecido da lâmina foliar verde em mais de $50 \%$ de sua extensão; colmo: colmo e bainha de perfilhos que emitirem ou não inflorescência; e material senescente: tecido necrosado em folha aderida ao perfilho e o material completamente necrosado não visivelmente aderido ao perfilho. Após a secagem, as amostras foram novamente pesadas para determinação da massa seca da forragem total e de seus constituintes, e cada fração foi expressa como porcentagem do peso total.

As pesagens dos animais foram realizadas a cada 28 dias, com jejum de 16 horas. O ganho de peso médio diário (GMD) foi obtido pela diferença entre a pesagem final e a inicial, dividido pelo número de dias do período. $\mathrm{O}$ ganho de peso por área (GPA) foi calculado multiplicando-se a média do ganho de peso médio diário pelo número médio de animais $\mathrm{ha}^{-1} \mathrm{e}$ o número de dias de pastejo. As variáveis climáticas de temperatura de globo negro (TG), temperatura do ar (TA), umidade relativa (UR) e temperatura radiante média (TRM) foram registradas a cada uma hora, por dataloggers da marca $\mathrm{HOBO}{ }^{\circledR}$ U12-012 (Onset, Rondonópolis/MT), que têm como características componentes de precisão que eliminam a necessidade de calibração pelo usuário. A velocidade do vento (VV) foi aferida pelo anemômetro digital de baixo custo LM81AM Lutron $\AA$, a cada uma hora, por um avaliador previamente treinado.

No sistema ILP, os equipamentos foram alocados no sol, no ILPF-1L e ILPF-3L foram colocados em pleno sol e na sombra. Os equipamentos foram alocados a $1,4 \mathrm{~m}$ do solo, simulando a altura do centro de massa de ruminantes de 
grande porte. As avaliações foram feitas nos tratamentos por 12 horas consecutivas, das seis às 18 horas. As médias dos tratamentos foram divididas em três períodos do dia (seis às nove horas, 10 às 13 horas e 14 às 18 horas). As avaliações foram realizadas em março de 2016, entre as estações verão e outono, por dois dias consecutivos. Após a avaliação, determinou-se o índice de temperatura e umidade (ITU), segundo Thom (1958), o índice de temperatura de globo e umidade (ITGU), de acordo com Buffington et al. (1981), e a carga térmica radiante (CTR), conforme Esmay (1979).

Para a coleta de sangue, as amostras foram obtidas utilizando-se tubos a vácuo, Vacutainer ${ }^{\circledR}$ de $5 \mathrm{~mL}$, com anticoagulante ácido etilenodiaminotetracético (EDTA), mediante punção da jugular. Imediatamente após a coleta, as amostras de sangue foram encaminhadas para o laboratório de análises clínicas do Hospital Veterinário de Andradina, Andradina - SP, para a determinação da proteína plasmática de acordo com Wolf et al. (1962) e a contagem global de leucócitos, de eritrócitos, plaquetas, hemoglobina, volume globular e linfócitos, realizadas pelo analisador hematológico veterinário automático Poch -100 iv Diff (Sysmex®). A coleta de sangue também foi realizada em março de 2016.

O delineamento experimental utilizado foi em blocos completos, com três tratametos e quatro repetições, totalizando 12 piquetes. Os dados foram submetidos às análises estatísticas, utilizando-se o programa SAS 9.4 (SAS..., 2013). Foi empregado o procedimento UNIVARIATE NORMAL, e a normalidade dos dados confirmada pelo teste de Shapiro-Wilk $(\mathrm{W} \geq 0,90)$. $\mathrm{Na}$ análise dos dados, o piquete foi considerado como unidade experimental para todas as variáveis analisadas. Os dados foram, então, analisados utilizando-se o procedimento PROC MIXED e a aproximação Satterthwaite para determinar os graus de liberdade para os testes de efeitos fixos. O sistema, o bloco, as estações e as interações (sistema $\times$ estação) foram considerados efeitos fixos para as variáveis de composição morfológica da forragem e desempenho. Para as variáveis climáticas foi considerado efeitos fixos o sistema, o bloco, o período e as interações (sistema $\times$ período) . E, para os parâmetros hematológicas foram considerados efeitos fixos apenas o sistema e o bloco, sendo o piquete considerado variável aleatória. As médias foram calculadas pelo procedimento lsmeans e os resultados foram relatados como mínimos quadrados e separados utilizando-se a opção probabilidade da diferença (PDIFF). O teste utilizado para testar as médias foi o teste de Tukey ao nível de significância de 5\%.

\section{RESULTADOS E DISCUSSÃO}

Os resultados da avaliação da pastagem estão expressos na Tab. 1. Não foram observadas interações entre os sistemas (ILP, ILPF-1L e ILPF-3L) e o período (verão e outono) para as avaliações da forragem e para o desempenho dos animais $(\mathrm{P}>0,05)$. Por outro lado, observou-se maior massa seca de forragem no tratamento ILP, quando comparado com os tratamentos ILPF-1L e ILPF-3L $(\mathrm{P}<0,05)$. Esses resultados concordam com Soares et al. (2009), que encontraram valores de massa seca de capimmarandu a pleno sol de $3477,2 \mathrm{~kg} \mathrm{ha}^{-1}$ e sob sombreamento natural de Pinus taeda (espaçamento $15 \times 3 \mathrm{~m}$ e $9 \times 3 \mathrm{~m}$ ) de $2483,2 \mathrm{~kg} \mathrm{ha}^{-1} \mathrm{e}$ $895,7 \mathrm{~kg} \mathrm{ha}{ }^{-1}$, respectivamente. A menor quantidade de massa seca nos menores espaçamentos arbóreos pode ser justificada pela baixa qualidade e quantidade de radiação que chega ao dossel no estrato inferior, além da competição por água (Soares et al., 2009; Bernardino e Garcia, 2009).

Em relação à estação, a massa de forragem foi maior no verão em relação ao outono devido ao fato de as condições climáticas serem mais favoráveis nessa época $(\mathrm{P}<0,05)$. No verão, a precipitação na área experimental foi de, aproximadamente, $378 \mathrm{~mm}$ e a temperatura variou de $21^{\circ}$ a $32^{\circ} \mathrm{C}$; já no outono, a precipitação foi de $172 \mathrm{~mm}$ e a temperatura de $17^{\circ}$ a $29^{\circ} \mathrm{C}$. Segundo Sherman e Riveros (1990), a temperatura ideal para o crescimento do capimmarandu é de 30 a $35^{\circ} \mathrm{C}$ e a mínima é de $15^{\circ} \mathrm{C}$. Assim, pode-se afirmar que as altas temperaturas, em associação com a maior precipitação no verão, contribuíram para a obtenção da maior massa de forragem nessa estação em relação ao outono. 
Tabela 1. Massa seca de forragem (MSF) e composição morfológica (folha, colmo e material senescente) de capim-marandu em sistemas integrados de produção agropecuária

\begin{tabular}{lcccc} 
Tratamentos & MSF $\left(\mathrm{kg} \mathrm{ha}^{-1}\right)$ & Folha $(\%)$ & Colmo $(\%)$ & Material senescente $(\%)$ \\
\hline ILP & $5186 \mathrm{a}$ & 17,40 & 28,20 & 54,40 \\
ILPF-1L & $3955 \mathrm{~b}$ & 18,90 & 30,20 & 50,90 \\
ILPF-3L & $4027 \mathrm{~b}$ & 18,40 & 30,00 & 51,60 \\
Verão & $4783 \mathrm{a}$ & $19,40 \mathrm{a}$ & $32,50 \mathrm{a}$ & $48,10 \mathrm{~b}$ \\
Outono & $3995 \mathrm{~b}$ & $16,90 \mathrm{~b}$ & $26,30 \mathrm{~b}$ & $56,80 \mathrm{a}$ \\
Sistema (S) & $<0,0001$ & 0,3798 & 0,1091 & 0,0826 \\
Estação (E) & $<0,0001$ & 0,0113 & $<0,0001$ & $<0,0001$ \\
S $\times$ E & 0,3774 & 0,9743 & 0,3833 & 0,7946 \\
EP & 85,34 & 0,27 & 0,41 & 0,57 \\
\hline
\end{tabular}

Médias seguidas de letras minúsculas distintas na coluna não diferem entre si pelo teste de Tukey a 5\%. EP = Erropadrão; ILP: integração lavoura-pecuária; ILPF-1L: integração lavoura-pecuária-floresta com linha simples de eucalipto; ILPF-3L: integração lavoura-pecuária-floresta com linhas triplas de eucalipto.

A composição morfológica do capim-marandu não foi afetada pela condição de sombreamento e não houve diferença entre os tratamentos $(\mathrm{P}>0,05)$. Esse fato pode estar relacionado com a capacidade de o capim-marandu ajustar-se ao comportamento fotossintético ao sombreamento (Dias-Filho, 2002). A porcentagem de folha e colmo foi maior no verão em relação ao outono $(\mathrm{P}<0,05)$, em razão de as condições climáticas serem mais favoráveis ao crescimento da forrageira. Por outro lado, o material senescente foi inversamente proporcional a ambos $(\mathrm{P}<0,05)$, em virtude da redução do aparecimento de folhas novas, que levou ao aumento de material senescente na planta. Flores et al. (2008) avaliaram as características estruturais da Urochloa brizantha cultivares Marandu e Xaraés submetidas a intensidades de pastejo e encontraram resultados semelhantes ao presente trabalho, exceto para a porcentagem de folhas, que foi semelhante nas estações do verão e outono.

Não foram observadas diferenças significativas entre os sistemas para ganho de peso médio diário (GMD), ganho de peso por área (GPA) e taxa de lotação (TL) (P>0,05; Tab. 2). Entretanto, no verão, o GMD, o GPA e a TL foram maiores que no outono $(\mathrm{P}<0,05)$, como consequência da maior disponibilidade de forragem e da maior porcentagem de folha $\mathrm{e}$ colmo disponíveis aos animais devido ao favorecimento das condições climáticas. Os resultados para TL foram semelhantes aos obtidos por Flores et al. (2008), que observaram maior TL no verão em relação ao outono devido à maior quantidade de animais necessária para manter o capim na altura pretendida $(15$ e $25 \mathrm{~cm})$.

Tabela 2. Ganho de peso médio diário (GMD), ganho de peso por área (GPA) e taxa de lotação (TL) de bovinos da raça Nelore terminados em sistemas integrados de produção agropecuária

\begin{tabular}{lccc}
\hline Tratamentos & GMD $(\mathrm{kg})$ & $\mathrm{GPA}\left(\mathrm{kg} \mathrm{ha}^{-1}\right)$ & $\mathrm{TL}\left(\mathrm{kg} \mathrm{ha}^{-1}\right)$ \\
\hline ILP & 0,47 & 241,16 & 1241 \\
ILPF-1L & 0,47 & 237,56 & 1203 \\
ILPF-3L & 0,46 & 206,86 & 1176 \\
Verão & $0,68 \mathrm{a}$ & $176,72 \mathrm{a}$ & $1384 \mathrm{a}$ \\
Outono & $0,26 \mathrm{~b}$ & $65,45 \mathrm{~b}$ & $1029 \mathrm{~b}$ \\
Sistema (S) & 0,9798 & 0,9362 & 0,7474 \\
Estação (E) & $<0,0001$ & $<0,0001$ & $<0,0001$ \\
S $\times$ E & 0,3814 & 0,366 & 0,9669 \\
EP & 0,02 & 0,03 & 91,00 \\
\hline
\end{tabular}

Médias seguidas de letras minúsculas distintas na coluna diferem entre si pelo teste de Tukey a 5\%. EP = Erropadrão;

ILP: integração lavoura-pecuária; ILPF-1L: integração lavoura-pecuária-floresta com linha simples de eucalipto; ILPF-3L: integração lavoura-pecuária-floresta com linhas triplas de eucalipto. 
Os dados referentes ao conforto térmico dos animais estão apresentados na Tab. 3. Não houve interação entre tratamento e período do dia $(\mathrm{P}>0,05)$. No entanto, velocidade do vento (VV) foi maior no tratamento ILP em relação ao ILPF1L sombra e ao ILPF-3L no sol e na sombra
$(\mathrm{P}<0,05)$. Esse fato pode ser justificado em razão de as árvores funcionarem como uma barreira física para o vento. Isso porque uma superfície coberta com vegetação segura o ar, de modo que, junto à superfície, a VV pode ser consideravelmente reduzida (Silva, 2000).

Tabela 3. Velocidade do vento (VV), temperatura de globo negro (TG), temperatura ambiente (TA), umidade relativa do ar (UR), carga térmica radiante (CTR), índice de temperatura e umidade (ITU) e índice de temperatura de globo negro e umidade (ITGU) durante três períodos do dia, em sistemas integrados de produção agropecuária

\begin{tabular}{lccccccc}
\hline Tratamentos & $\mathrm{VV}\left(\mathrm{m} \mathrm{s}^{-1}\right)$ & $\mathrm{TG}\left({ }^{\circ} \mathrm{C}\right)$ & $\mathrm{TA}\left({ }^{\circ} \mathrm{C}\right)$ & $\mathrm{UR}(\%)$ & $\mathrm{CTR}\left(\mathrm{W} \mathrm{m}^{-2}\right)$ & $\mathrm{ITU}$ & ITGU \\
\hline ILP & $0,94 \mathrm{a}$ & $39,69 \mathrm{a}$ & $33,23 \mathrm{a}$ & $45,83 \mathrm{~b}$ & 462,77 & $83,91 \mathrm{a}$ & 88,28 \\
ILPF-1L sol & $0,79 \mathrm{ab}$ & $37,68 \mathrm{a}$ & $32,12 \mathrm{~b}$ & $49,59 \mathrm{a}$ & 530,52 & $81,38 \mathrm{bc}$ & 86,71 \\
ILPF-1L som. & $0,59 \mathrm{bc}$ & $34,62 \mathrm{ab}$ & $31,62 \mathrm{bc}$ & $51,23 \mathrm{a}$ & 513,43 & $81,01 \mathrm{bc}$ & 84,24 \\
ILPF-3L sol & $0,54 \mathrm{c}$ & $39,61 \mathrm{a}$ & $32,14 \mathrm{~b}$ & $51,37 \mathrm{a}$ & 554,68 & $81,75 \mathrm{~b}$ & 88,21 \\
ILPF-3L som. & $0,55 \mathrm{c}$ & $33,27 \mathrm{~b}$ & $31,03 \mathrm{c}$ & $51,99 \mathrm{a}$ & 502,38 & $80,44 \mathrm{c}$ & 82,71 \\
& & \multicolumn{7}{c}{ Período (horas) } \\
06:00 às 09:00 & $0,18 \mathrm{c}$ & $27,23 \mathrm{c}$ & $24,48 \mathrm{c}$ & $71,68 \mathrm{~b}$ & $450,08 \mathrm{c}$ & $74,17 \mathrm{c}$ & $77,50 \mathrm{c}$ \\
10:00 às 13:00 & $1,21 \mathrm{a}$ & $44,24 \mathrm{a}$ & $36,66 \mathrm{a}$ & $39,20 \mathrm{a}$ & $575,83 \mathrm{a}$ & $86,60 \mathrm{a}$ & $93,98 \mathrm{a}$ \\
14:00 às 18:00 & $0,66 \mathrm{~b}$ & $39,26 \mathrm{~b}$ & $34,95 \mathrm{~b}$ & $39,13 \mathrm{a}$ & $512,36 \mathrm{~b}$ & $84,32 \mathrm{~b}$ & $86,63 \mathrm{~b}$ \\
Sistema (S) & 0,0057 & 0,0068 & $<0,0001$ & 0,0085 & 0,0706 & $<0,0001$ & 0,1146 \\
Período (P) & $<0,0001$ & $<0,0001$ & $<0,0001$ & $<0,0001$ & $<0,0001$ & $<0,0001$ & $<0,0001$ \\
S $\times$ P & 0,1218 & 0,4323 & 0,6818 & 0,0975 & 0,7331 & 0,0948 & 0,3837 \\
EP & 0,07 & 1,35 & 0,82 & 2,40 & 13,52 & 0,87 & 1,83 \\
\hline
\end{tabular}

Médias seguidas de letras distintas nas colunas diferem entre si pelo teste de Tukey a 5\%. EP = Erro-padrão; ILP: integração lavoura-pecuária; ILPF-1L: integração lavoura-pecuária-floresta com linha simples de eucalipto (sol; som. = sombra); ILPF-3L: integração lavoura-pecuária-floresta com linhas triplas de eucalipto (sol; som. = sombra).

A TG foi menor no sistema ILPF-3L sombra comparada aos outros sistemas $(\mathrm{P}<0,05)$ devido à maior quantidade de árvores que, consequentemente, proporcionam maior sombreamento, sendo a maior temperatura no período das 10 às 13 horas $(\mathrm{P}<0,05)$. A TG fornece uma estimativa dos efeitos combinados da energia térmica radiante consequente do meio ambiente em todas as direções possíveis, da TA e da VV, dando, assim, uma medida de conforto térmico proporcionado pelo ambiente nessas determinadas condições (Silva, 2000), ou seja, esse parâmetro representa a sensação térmica do ambiente no qual o animal está inserido. Assim, os tratamentos com sombra apresentaram melhores condições de conforto térmico aos animais, pois proporcionaram redução na $\mathrm{TG}$ de até $6,4^{\circ} \mathrm{C}$ em relação à ILP e, apesar de todos os valores estarem elevados, verifica-se que a presença de árvores pode amenizar significativamente a condição de estresse térmico.

A TA foi maior no tratamento de ILP e menor no ILPF-3L sombra $(\mathrm{P}<0,05)$. O gado zebuíno, a partir de $27^{\circ} \mathrm{C}$, ativa mecanismos termorreguladores e, acima de $35^{\circ} \mathrm{C}$, esses mecanismos começam a falhar, afetando a produção de carne ou de leite (Alves et al., 2015). E então, pode-se assegurar que os animais de todos os tratamentos estão em desconforto térmico no período após as 10 horas da manhã. Por outro lado, pode-se afirmar que, apesar de a TA estar elevada, a UR não está dificultando a dissipação do calor dos animais, uma vez que a evaporação cutânea em gado zebuíno fica deprimida sob UR alta associada à temperatura superior de $32^{\circ} \mathrm{C}$ a $35^{\circ} \mathrm{C}$ (Medeiros e Vieira, 1997).

Resultados semelhantes foram encontrados por Navarini et al. (2009), ao avaliarem sistemas com e sem sombra no estado do Paraná, os quais obtiveram TA de $26,9^{\circ} \mathrm{C}, 28,6^{\circ} \mathrm{C}$ e $30,5^{\circ} \mathrm{C}$ para os tratamentos de pequenos bosques, árvores isoladas e pleno sol, respectivamente. Esses autores ainda afirmaram que a diminuição da TA e da TG e o aumento da UR nos tratamentos com sombra estão relacionados com a redução da incidência de radiação solar proporcionada pela 
presença das árvores, o que torna o ambiente com melhores condições térmicas.

Em relação ao período, a TA apresentou-se menor no período das seis às nove horas; comportamento inverso foi encontrado para UR nesse mesmo período $(\mathrm{P}<0,05)$. Os resultados corroboram os evidenciados por Lopes et al. (2016), que, ao avaliarem as condições microclimáticas em pasto aberto e em sistemas integrados com a presença de árvores, observaram menores valores de TA e maiores valores de UR no período da manhã.

A carga térmica radiante (CTR) não apresentou diferença estatística entre os tratamentos $(\mathrm{P}>0,05)$, porém, em relação aos períodos, foi maior das 10 às 13 horas. $\mathrm{O}$ mesmo comportamento foi evidenciado por Martins et al. (2002), os quais avaliaram a qualidade térmica de algumas espécies arbóreas usando dados climáticos e índices de conforto térmico animal e observaram que a CTR foi maior nos horários das 12 às 14 horas.

O ITU foi maior no tratamento ILP e inferior no ILPF-1L e no ILPF-3L ( $\mathrm{P}<0,05)$, tanto no sol como na sombra, mostrando a importância das árvores para a melhoria do conforto térmico dos animais. Ainda com base nos valores de ITU, observou-se que foram considerados moderados (79 a 88), de acordo com a classificação de Hahn e Mader (1997) para o ambiente térmico de bovinos. Normalmente esses valores não causam problemas em animais saudáveis (Navarini et al.,
2009), entretanto, se for considerado o período, o horário mais crítico é das 10 às 13 horas, observando-se ITU de 86,6 próximo ao limite entre moderado e severo.

O ITGU não apresentou diferença significativa entre os tratamentos $(\mathrm{P}>0,05)$, apenas entre os períodos, sendo maior no período das 10 às 13 horas $(\mathrm{P}<0,05)$. Segundo Baêta (1985), índices de 79 a 84 indicam situação perigosa e acima de 84 indicam emergência. Observa-se que os dados obtidos no presente estudo foram superiores a 84 , o que mostra que os animais, de acordo com a escala, estavam em situação de emergência e que somente na ILPF-3L sombra os animais estavam em situação perigosa $(82,71)$.

Apesar dos índices de conforto térmico (ITU e ITGU) apresentarem-se elevados, não foi observada redução do ganho de peso nos animais que permaneceram sem sombra (ILP) e com sombra (ILPF-1L e ILPF-3L). Isso pode ser explicado pelo fato de o gado zebuíno ser altamente adaptado ao clima tropical, em virtude de possuírem maior número de glândulas sudoríparas e maior área de superfície que bovinos europeus, o que facilita a dissipação do calor (Zanette e Kruger, 2011). Todos os parâmetros hematológicos (Tab. 4) encontram-se dentro dos padrões de normalidade para a espécie (Schalm et al., 1975), com exceção da hemoglobina, que foi maior em todos os tratamentos, porém não exibiu diferenças estatísticas entre eles $(\mathrm{P}>0,05)$.

Tabela 4. Parâmetros hematológicos de novilhos da raça Nelore em sistemas integrados de produção agropecuária

\begin{tabular}{|c|c|c|c|c|c|}
\hline \multirow{2}{*}{ Parâmetros* } & \multicolumn{3}{|c|}{ Tratamentos } & \multirow{2}{*}{ EP } & \multirow{2}{*}{$P$-value } \\
\hline & ILP & ILPF-1L & ILPF-3L & & \\
\hline Leucócitos $\left(4-12 \times 10^{3} \mu 1^{-1}\right)$ & 11,74 & 10,61 & 11,72 & 0,83 & 0,3329 \\
\hline Volume globular (24-46\%) & $39,19 \mathrm{~b}$ & $41,44 \mathrm{a}$ & $41,77 \mathrm{a}$ & 0,61 & 0,0214 \\
\hline Linfócitos $(45-75 \%)$ & 64,52 & 62,85 & 61,13 & 1,79 & 0,3423 \\
\hline Plaquetas $\left(100-700 \times 10^{3} \mu \mathrm{L}^{-1}\right)$ & 374,72 & 276,58 & 311,36 & 14,76 & 0,1219 \\
\hline Proteína plasmática $\left(60-85 \mathrm{gL}^{-1}\right)$ & 70,52 & 68,77 & 70,47 & 0,42 & 0,4280 \\
\hline Eritrócitos $\left(5-10 \times 10^{6} \mu 1^{-1}\right)$ & 10,21 & 9,78 & 9,94 & 0,53 & 0,7551 \\
\hline Hemoglobina $\left(8-10 \mathrm{gdL}^{-1}\right)$ & 13,79 & 13,43 & 13,66 & 0,23 & 0,1327 \\
\hline
\end{tabular}

Médias seguidas de letras distintas nas linhas diferem entre si pelo teste de Tukey a 5\%. EP = Erro-padrão; *Valores entre parênteses são os de referência para bovinos, para a variável descrita (Schalm et al., 1975). ILP: integração lavoura-pecuária; ILPF-1L: integração lavoura-pecuária-floresta com linha simples de eucalipto; ILPF-3L: integração lavoura-pecuária-floresta com linhas triplas de eucalipto.

Apenas foi observada diferença entre os tratamentos para o volume globular, sendo encontrado valor inferior na ILP $(\mathrm{P}<0,05)$. O volume globular é uma mensuração laboratorial 
comumente utilizada para avaliar o grau de desidratação do animal (Blazius, 2008), que pode ser atribuído a vários fatores, entre eles ao estresse calórico. Menor valor de volume globular pode ser relacionado à maior hemodiluição causada pelo alto consumo de água pelos animais, quando submetidos ao estresse calórico (Brasil et al., 2000). Resultados semelhantes para essa variável foram encontrados por Singh et al. (2016), que, ao avaliarem o estresse térmico em ovinos de vários grupos genéticos, encontraram valores inferiores na estação quente comparada à estação fria, o que reforça que os animais do sistema ILP encontavam-se em algum grau de estresse calórico.

\section{CONCLUSÃO}

Os sistemas de ILPF com duas densidades de árvores (196 e 448 árvores ha $^{-1}$ ) reduzem a quantidade de massa de forragem em relação ao sistema de ILP, porém essa redução não é capaz de alterar o desempenho de bovinos da raça Nelore na fase de terminação. Além disso, por apresentarem o componente arbóreo, esses sistemas melhoram o conforto térmico dos animais, evidenciado pelo aumento da umidade relativa do ar e pela redução dos índices de temperatura do sistema e do volume globular sanguíneo dos animais. No entanto, essa melhora não foi suficiente para favorecer o desempenho dos bovinos.

\section{REFERÊNCIAS}

ALVES, F.V.; NICODEMO, M.L.F.; SILVA, V.P. Bem-estar animal em sistema de integração lavourapecuária-floresta. In: CORDEIRO, L.A.M.; VILELA, L.; KLUTHCOUSKI, J.; MARCHÃO, R.L. (Eds.). Integração lavoura-pecuária-floresta: $\mathrm{o}$ produtor pergunta, a Embrapa responde. Brasília, DF: Embrapa, 2015. p.273-289.

ANUÁRIO da pecuária brasileira. São Paulo: FNP Consultoria/Agros Comunicação, 2018. 280p.

BAÊTA, F.C. Responses of lactating dairy cows to the combined effects of temperature, humidity and wind velocity in the warm season. 1985. 218f. Thesis (Doctor Ph.D. in Agricultural Engineering-Structures and Environment) - University of Missouri, Columbia, EUA.
BALBINO, L.C.; CORDEIRO, L.A.M.; PORFÍRIODA-SILVA, V.; et al. Evolução tecnológica e arranjos produtivos de sistemas de integração lavoura-pecuária-floresta no Brasil. Pesqui. Agropecu. Bras., v.46, p.1-12, 2011.

BERNARDINO, F.S.; GARCIA, R. Sistemas silvipastoris. Pesqui. Florestal Bras. Colombo, Ed. Esp.n.60, p.77-87, 2009.

BLAZIUS, R.D. Fluidoterapia em grandes animais. In: Seminário apresentado na disciplina transtornos metabólicos dos animais domésticos, no programa de pós-graduação em ciências veterinárias da universidade do rio grande do sul, 2008, Porto Alegre. Anais... Porto Alegre: Universidade do Rio Grande do Sul, 2008.

BRASIL, L.H.A.; WECHESLER, F.S.; BASCCARI JÚNIOR, F.; GONÇALVES, H.C. et al. Efeitos do estresse térmico sobre a produção, composição química do leite e respostas termorreguladoras de abras da aça Alpina. Rev. Bras. Zootec., v.29, p.1632$1641,2000$.

BUFFINGTON, D.E.; COLLAZO-AROCHO, A.; CANTON, G.H. et al. Black-Globe-Humidity Index (BGHI) as comfort equation for dairy cows. Biol. Eng. Trans., v.24, p.711-714, 1981.

CASTRO FILHO, C.; LOURENÇO, A.; GUIMARÃES, M.D.F.; FONSECA, I.C.B. Aggregate stability under different soil management systems in a Red Latosol in the state of Paraná, Brazil. Soil Tillage Res., v.65, p.45-51, 2002.

CRUSCIOL, C.A.C.; NASCENTE, A.S.; MATEUS, G.P.; PARIZ, C.M. et al. Intercropping soybean and palisade grass for enhanced land use efficiency and revenue in a no till system. Eur. J. Agron., v.58, p.5362, 2014.

DIAS-FILHO, M.B. Photosynthetic light response of the C4 grasses Brachiaria brizantha and $B$. humidicola under shade. Sci. Agric., v.59, p.65-68, 2002.

ESMAY, M.L. Principles of animal environment. West Port: C.T. Avi Publishing, 1979. 325p.

FLORES, R.S.; EUCLIDES, V.P.B.; ABRÃO, M.P.C.; et al. Desempenho animal, produção de forragem e características estruturais dos capins marandu e xaraés submetidos a intensidades de pastejo. Rev. Bras. Zootec., v.37, p.1355-1365, 2008.

HAHN, G.L.; MADER, T.L. Heat waves in relation to thermoregulation, feeding behavior and mortality of feedlot cattle. In: PROCEEDINGS OF THE INTERNATIONAL LIVESTOCK ENVIRONMENT SYMPOSIUM MINNEAPOLIS, 5., 1997, Minneapolis. Proceedings... St. Joseph: ASAE, 1997. p.563-567. 
KICHEL, A.N.; COSTA, J.A.A.; ALMEIDA, R.G.; PAULINO, V.T. Sistema de integração lavourapecuária-floresta (ILPF) - experiências no Brasil. Bol. Ind. Anim., v.71, p.94-105, 2014.

LAL, R. Tillage and agricultural sustentability. Soil Tillage Res., v.20, p.133-146, 1991.

LOPES, L.B.; ECKSTEIN, C.; PINA, D.S.; CARNEVALLI, R.A. The influence of trees on the thermal environment and behaviour of grazing heifers in Brazilian Midwest. Trop. Anim. Health Prod., v.48, p.755, 2016.

LUZ, P.A.C.; ANDRIGHETTO, C.; LUPATINI, G.C.; ARANHA, H.S. et al. Effect of integrated croplivestock systems in carcass and meat quality of Nellore cattle. Livest. Sci., v.220, p.83-92, 2019.

MARTINS, J.L.; SILVA, I.J.O.; FAGNANI, M.A.; MOURA, D.J. et al. Avaliação da qualidade do sombreamento natural em pastagem no outono. Eng. Rural, v.13, único, 2002.

MEDEIROS, L.F.D.; VIEIRA, D.H. Bioclimatologia animal. Rio de Janeiro: UFRRJ, 1997. 126p.

MITLÖHNER, F.M.; GALYEAN, M.L.; MCGLONE, J.J. Shade effects on performance, carcass traits, physiology, and behaviour of heat-stressed feedlot heifers. J. Anim. Sci., v.80, p.2043-2050, 2002.

MORAES, A.; CARVALHO, P.C.F.; ANGHINONI, I.; LUSTOSA, S.B.C. et al. Integrated crop-livestock systems in the Brazilian subtropics. Eur. J. Agron., v.57, p.4-9, 2014.

MOTT, G.O.; LUCAS, H.L. The design, conduct, and interpretation of grazing trials on cultivated and improved pastures. IN: INTERNATIONAL GRASSLAND CONGRESS, 6., 1952. State College. Proceedings... State College: State College Presa, 1952.

NAVARINI, F.C.; KLOSOWSKI, E.S.; CAMPOS, A.T.; TEIXEIRA, R.A. et al. Conforto térmico de bovinos da raça nelore a pasto sob diferentes condições de sombreamento e a pleno sol. Eng. Agríc., v.29, p.508-517, 2009.
PIRES, M.F.A.; PACIULLO, D.S.C.; PIRES, J.A.A. Conforto animal no Sistema Integração LavouraPecuária-Floresta. Inf. Agropecu., v.31, p.81-89, 2010.

PORFÍRIO-DA-SILVA, V. Sistemas silvipastoris em Mato Grosso do Sul. Para que adota-los? In: SEMINÁRIO SISTEMAS AGROFLORESTAIS E DESENVOLVIMENTO SUSTENTÁVEL, 2003. Anais... Campo Grande: Embrapa-Gado de Corte, 2003. p.1-13.

SAS user's guide: statistics. Version 9.4. Cary: SAS Institute, 2013.

SCHALM, O.W.; JAIN, N.C.; CARROL, E.J. Hematologia veterinária. 3.ed. Philadelphia: Lea \& Febiger, 1975.

SHERMAN, P.J.; RIVEROS, F. Tropical grasses. Roma: FAO, 1990. 832p.

SILVA, R.G. Introdução a bioclimatologia animal. São Paulo: Nobel, 2000. p.286.

SINGH, K.M.; SINGH, S.; GANGULY, I.; GANGULY, A. et al. Evaluation of Indian sheep breeds of arid zone under heat stress condition. Small Ruminant Res., v.141, p.113-117, 2016.

SOARES, A.B.; SARTOR, L.R.; ADAMI, P.F.; VARELLA, A.C. et al. Influência da luminosidade no comportamento de onze espécies forrageiras perenes de verão. Rev. Bras. Zootec., v.38, p.443-451, 2009.

THOM, E.C. The discomfort index. Weatherwise, v.12, p.57-59, 1958.

WOLF, A.V.; FULLER, J.B.; GOLDMAN, E.J.; MAHONY, T.D. New refractometric methods for determination of total proteins in serum and in urine. Clin. Chem., v.8, p.158-165, 1962.

ZANETTE, P.M.; KRUGER, M.G. Sistema silvipastoril como alternativa para a produção de bovinos de corte. 2011. 27f. Trabalho de Conclusão de Curso (Pós Graduação Lato Sensu em Produção de Bovinos) - Faculdade de Ciências Biológicas e de Saúde, Universidade Tuiuti do Paraná, PR. 